\title{
CAP-APL: Plataforma para criação e uso de arquiteturas pedagógicas para aprendizagem de Português e Libras
}

\author{
Orivaldo de Lira Tavares ${ }^{1}$, Luiz Fernando Reinoso ${ }^{2}$, Wanderson Rocha de Almeida ${ }^{1}$ \\ ${ }^{1}$ Programa de Pós-Graduação em Informática - UFES - Vitória - ES - Brasil \\ ${ }^{2}$ Coordenadoria de Informática - IFES - Colatina - ES - Brasil \\ tavares@inf.ufes.br, luizfreinoso@gmail.com,wander25rda@gmail.com
}

\begin{abstract}
This paper presents CAP-APL, a web platform that provides digital resources for the creation and use of pedagogical architectures (APS) for learning Portuguese and Libras (Brazilian Sign Language). This platform, with its architecture and services, is presented in this work, as well as the creation and use of APs for learning Portuguese and Libras.
\end{abstract}

Resumo. Este artigo apresenta a CAP-APL, uma plataforma web que disponibiliza recursos digitais para a criação $e$ uso de arquiteturas pedagógicas (APS) para a aprendizagem de Português e Libras (Lingua Brasileira de Sinais). Essa plataforma, com sua arquitetura e serviços, é apresentada neste trabalho, bem como a criação e uso de APs para a aprendizagem de Português e Libras.

\section{Introdução}

O uso da internet e a difusão de tecnologias digitais têm sido intensificados em diversas áreas da atividade humana e, em especial, na educação. Isso vem aumentando o interesse para o uso de espaços virtuais, nos quais seja possível ao professor, leigo em informática, criar atividades a serem realizadas na web pelos alunos de suas disciplinas. Este trabalho apresenta a plataforma web CAP-APL que permite ao professor criar Arquiteturas Pedagógicas (APs), e ao aprendiz, usar essas APs para desenvolver atividades que o levem a atingir um objetivo de aprendizagem.

As arquiteturas pedagógicas (APs) são suportes estruturantes à aprendizagem propostos por Carvalho et al. (2005), focados na construção do conhecimento, de ideias construtivistas, de Jean Piaget (1985), e de incentivo à autonomia, de Paulo Freire (1988). As APs são estruturas de aprendizagem compostas pela abordagem pedagógica, software, internet, inteligência artificial, educação à distância e concepção de tempo e espaço. Acolhem didáticas flexíveis, maleáveis e adaptáveis a diferentes temas. As perspectivas de tempo e espaço de aprendizagem passam a se moldar aos ritmos impostos pelo sujeito que aprende, removendo a exigência pela localização em escola ou sala de aula.

As arquiteturas funcionam como mapas, mostrando diferentes possibilidades de se realizar algo, fornecendo ao aprendiz a escolha dos caminhos a serem percorridos. Os professores são essenciais para a criação e reinvenção dessas arquiteturas pedagógicas. Já os aprendizes atuam como protagonistas, agindo e refletindo sobre experiências com a orientação do professor.

Os autores definem uma arquitetura pedagógica como uma estrutura de aprendizagem, concebida com conceitos construtivistas e com o uso de recursos 
VI Congresso Brasileiro de Informática na Educação (CBIE 2017)

Anais do XXVIII Simpósio Brasileiro de Informática na Educação (SBIE 2017)

digitais, composta por: 1) objetivo de aprendizagem (o que aprender); 2) atividades (o que fazer); 3) método (como fazer as atividades com os recursos digitais) e 4) recursos digitais (com que ferramentas).

Para o desenvolvimento da plataforma CAP-APL (Construtor de arquiteturas pedagógicas para aprendizagem de Português e LIBRAS - Língua Brasileira de Sinais) foi realizado um estudo etnográfico [Cervo et al., 2007], partindo de análises de documentos institucionais e atividades da disciplina 'Introdução a LIBRAS', ofertada a alunos de um curso técnico. A partir desse levantamento inicial, foi feita a especificação inicial de requisitos do sistema, análise e projeto da CAP-APL, que faz uso do Framework CAP [Reinoso et al., 2016], seu modelo e arquitetura, com reúso do banco de dados e funcionalidades da framework, possibilitando a implementação de protótipos.

O Framework Construtor de Arquiteturas Pedagógicas (CAP) possibilita a criação de arquiteturas pedagógicas virtuais, permitindo a um professor, mesmo leigo em informática, gerar um conjunto de atividades e implementar uma AP com recursos digitais que a suportem. A Framework permite ao professor alocar recursos e configurálos, do modo mais adequado, para suportar a AP especificada por ele [Reinoso et al., 2016].

As funções disponíveis em um Construtor de Arquiteturas Pedagógicas (CAP) permitem, ao professor, definir e, aos aprendizes, realizarem atividades individuais ou colaborativas. $\mathrm{O}$ modelo é oriundo de pesquisas aprofundadas nos elementos, propostas e conceitos do projeto MOrFEu [Menezes et al. 2008, Santos et al. 2010], um acrônimo para Multi-Organizador Flexível de Espaços Virtuais, onde são usadas estruturas computacionais flexíveis que possibilitam a edição e configuração de ambientes digitais.

No estudo acerca de tecnologias para suporte a aprendizagem de LIBRAS, notase uma concentração na concepção de tecnologias voltadas a tradução bidirecional entre emissor e receptor. Elas fazem uso de leitores de tela com avatares virtuais, como o ProDeaf e Handtalk [Santarosa, 2014] que apresentam sinais Libras de forma animada, vídeos ou figuras segmentadas. Esses recursos, quando sequenciados corretamente, conseguem gerar traduções para sentenças e textos completos [Coradine et al., 2004][Sampaio et al., 2015]. O uso dessas tecnologias deve ser citado devido a atual facilidade de acesso e disponibilidade.

O CAP-APL foi desenvolvido para suprir as demandas de Processamento de Linguagem Natural, possibilitando trabalhar a aprendizagem de Português e LIBRAS, importantes para formação de intérpretes e tradutores LIBRAS.

Este artigo apresenta alguns serviços de uma plataforma de serviços web CAPAPL, que disponibiliza recursos de PLN para o Português, bem como, recursos digitais úteis para a aprendizagem de LIBRAS. Esses serviços, apresentados na seção 2, foram implementados pelos autores e usados na criação de APs para a aprendizagem de Português que os demandem, como as arquiteturas pedagógicas AP1 e AP2 apresentadas na seção 4.

Este artigo também apresenta, na seção 3, um tradutor de Português para Libras, implementado pelos autores, usado na criação de arquiteturas pedagógicas que demandem esse recurso, tal como a AP3 apresentada na seção 4. 
VI Congresso Brasileiro de Informática na Educação (CBIE 2017)

Anais do XXVIII Simpósio Brasileiro de Informática na Educação (SBIE 2017)

Com esses recursos digitais, foi possível a elaboração de várias arquiteturas pedagógicas (APs) para a aprendizagem de Português, de Libras e de tradução de Português para Libras, apresentadas na seção 4.

Usando a plataforma CAP que implementa um modelo de construção de APs, equipada com os recursos digitais apresentados na seção 3 , os autores criaram a CAPAPL, uma plataforma para a criação e uso de arquiteturas pedagógicas para a aprendizagem de Português e Libras. Com a plataforma CAP já foram construídas outras plataformas para criação e uso de arquiteturas pedagógicas em outros contextos educacionais, tal como a apresentada em Almeida et al (2016) - uma plataforma para a construção de arquiteturas pedagógicas para dinâmicas colaborativas com dados multimídia.

\section{Plataforma CAP (Construtor de Arquiteturas Pedagógicas)}

A Figura 1 apresenta a arquitetura da CAP [Reinoso et al., 2016]. Essa arquitetura usa os conceitos definidos pelo modelo Morfeu [Menezes et al., 2008]. Com o uso da CAP o professor pode criar uma AP, configurando seus recursos. Cada nova AP constitui-se de UPIs (Unidades de Produção Intelectual) e recursos digitais. As UPIs da AP definem a identificação da AP, o objetivo pedagógico, as atividades e seus métodos. Essas UPIs são organizadas em um VCom (com UPIs e os respectivos recursos digitais) que compõe a AP.

\section{Plataforma CAP}

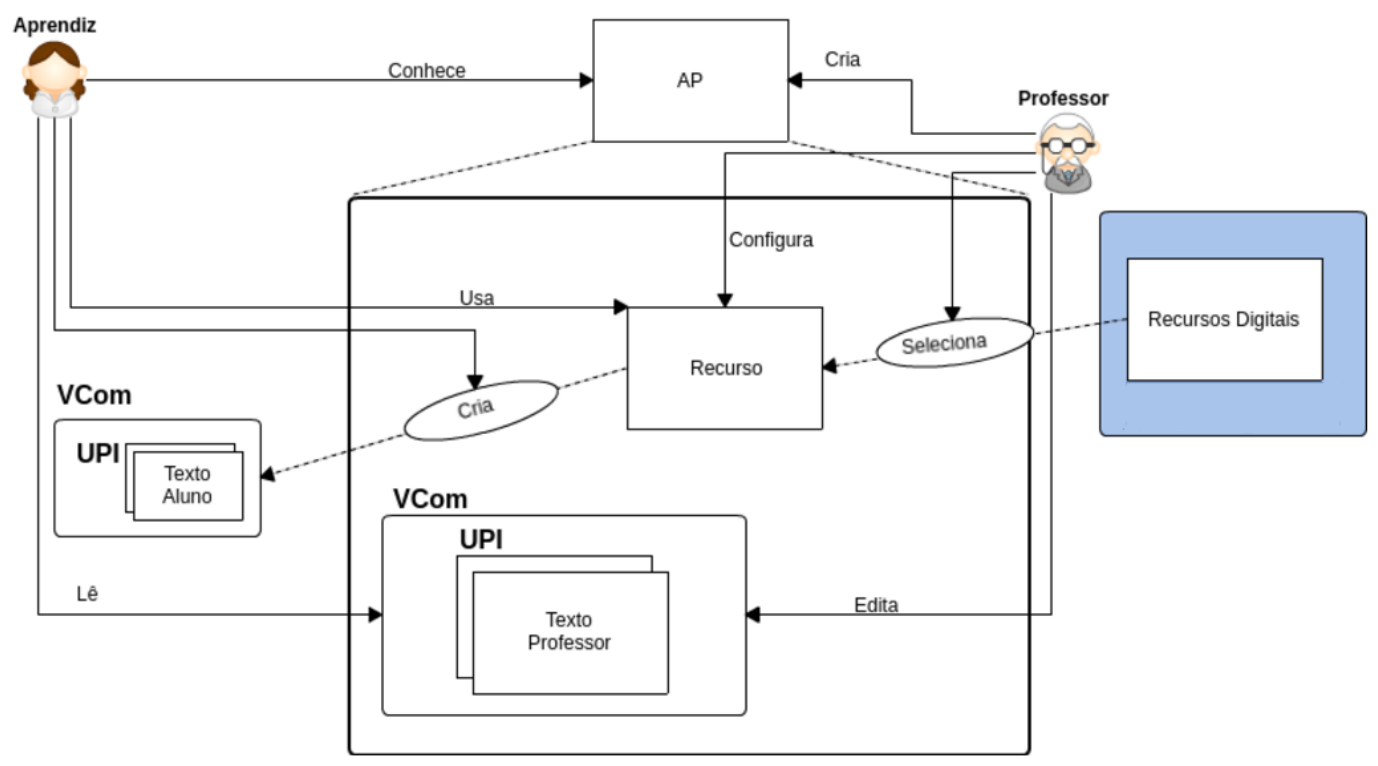

Figura 1. Arquitetura da plataforma CAP (Fonte: Reinoso et al. (2016)).

Segundo Nascimento et al. (2012), uma UPI, criada para cada texto (multimídia) produzido por um usuário, possui propriedades que formalizam as atividades do usuário, de modo que uma mesma UPI possa ser publicada em diferentes formas de apresentação.

Um VCom é um veículo de comunicação entre pessoas que nele assumem papéis, às vezes simultaneamente, de criadores e consumidores de conteúdo (Pereira, 
VI Congresso Brasileiro de Informática na Educação (CBIE 2017)

Anais do XXVIII Simpósio Brasileiro de Informática na Educação (SBIE 2017)

2015). Alguns exemplos de VComs são: aplicativos de publicação de mensagem, blogs da internet, redes sociais digitais, revistas, relatório de uma aula de campo, mapas mentais etc.

Na Figura 1 vemos que uma AP, criada na plataforma CAP, é composta por textos do professor (criador da AP) e recursos digitais selecionados por ele. O aprendiz, ao usar a AP, produz textos. Todos os textos são gerenciados pela CAP, na forma de UPIs.

Os recursos digitais selecionados e configurados pelo professor, são agregados à AP. O professor pode ajustar as UPIs da AP quando desejar. Os recursos digitais gerenciados pelo professor dão suporte aos alunos no desenvolvimento das atividades. A Biblioteca de Recursos Digitais (BRD) possui os recursos implementados de acordo com a demanda do professor. Um novo recurso digital pode ser criado/atualizado sem afetar as composições anteriores dos alunos e professores, pois quando o professor seleciona e configurar o recurso, essas informações são armazenadas em uma instância criada do recurso para a nova AP, o que permite a manutenção e atualização da BRD da CAP, sem prejuízos das APs existentes.

Usando a plataforma CAP equipada com os recursos digitais apresentados na seção 3, os autores criaram a CAP-APL, uma plataforma para a criação e uso de arquiteturas pedagógicas para a aprendizagem de Português e Libras.

\section{Recursos digitais para aprendizagem de Português e de Libras}

Esta seção apresenta os recursos digitais, incluídos na Biblioteca de Recursos Digitais (BRD) da CAP, que viabilizam a criação de APs para a aprendizagem de Português e de Libras. Os recursos digitais usados na aprendizagem de Libras, incluídos na BRD, estão apresentados em Reinoso et al. (2015) e em Reinoso (2016). Os recursos digitais usados na aprendizagem de Português são selecionados de uma plataforma de serviços web que disponibiliza recursos de PLN para o Português - o PortService-BR, implementada pelos autores e disponível em http://portservice.pythonanywhere.com/. Esses serviços são apresentados a seguir:

1. Etiquetador de palavras que recebe um texto em português e retorna o texto com suas palavras etiquetadas (classe gramatical, gênero, número etc);

2. Lematizador que recebe uma palavra e retorna o lema dela;

3. Gerador de synset (um identificador de uma classe de palavras sinônimas) que recebe uma palavra e, com a ajuda de uma WordNet (WordNet, 2015), retorna o synset dessa palavra;

4. Apresentador da classe de um synset: recebe um synset e retorna as palavras sinônimas representadas por ele.

Este artigo também apresenta um tradutor de Português para Libras (Língua Brasileira de Sinais), disponível como uma API do PortService-BR e apresentado na Figura 2, que trabalha com três passos: $1^{\circ}$. tradução baseada em exemplos (usa uma Memória de Tradução), $2^{\circ}$. tradução baseada em sinonímia (usa expressões sinônimas pela substituição das palavras de uma expressão pelos synsets delas) e $3^{\circ}$. tradução baseada em regras. A tradução é feita com o procedimento do passo $1 \mathrm{e}$, se não for possível, com o procedimento do passo 2 e, se não for possível, com o do passo 3 . Se 
VI Congresso Brasileiro de Informática na Educação (CBIE 2017)

Anais do XXVIII Simpósio Brasileiro de Informática na Educação (SBIE 2017)

nenhum passo se aplicar, a expressão é guardada para, em uma etapa de manutenção, ser incluída como um novo exemplo na Memória de Tradução (MT). A Figura 2, exemplifica o funcionamento do tradutor.

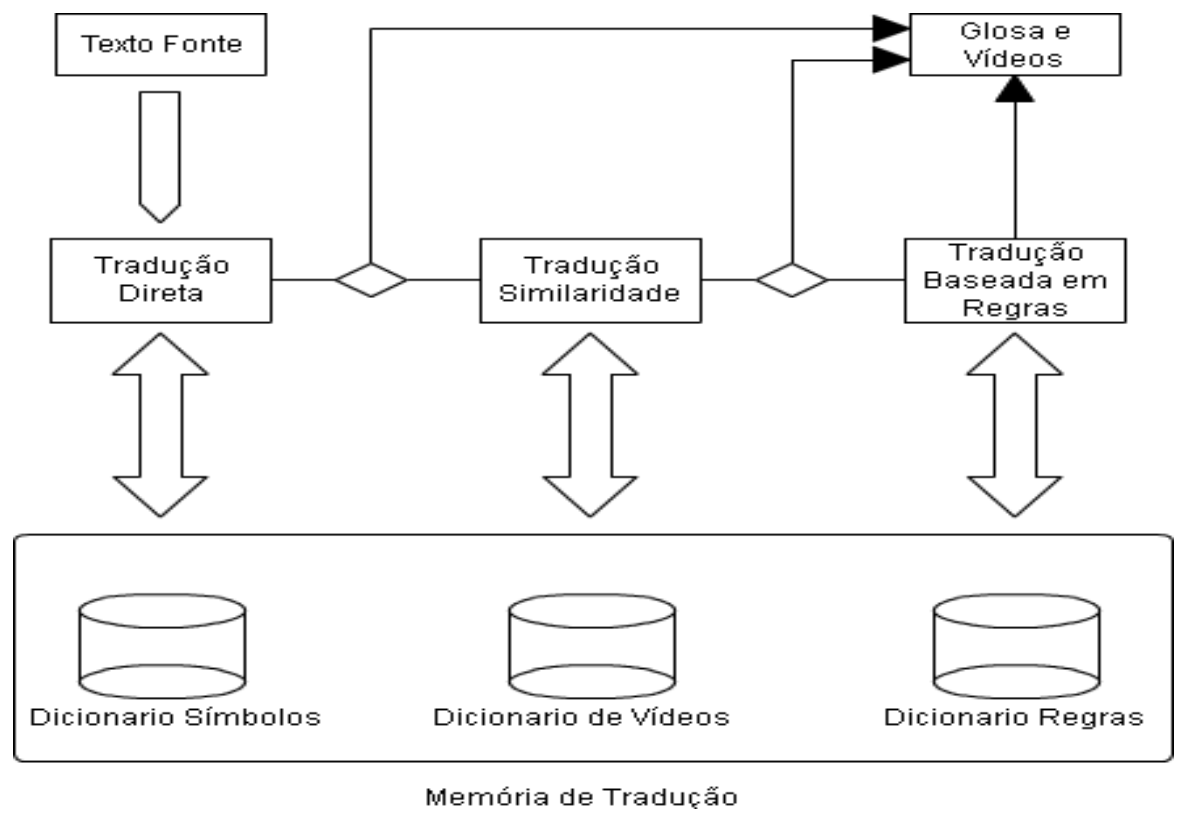

Figura 2. Exemplo do funcionamento do sistema de tradução da CAP-APL.

Usando a plataforma CAP (Figura 1) que implementa um modelo de construção de APs, equipada com os recursos digitais apresentados e com outros recursos adicionais como um gravador de vídeos, um visualizador de vídeos, um visualizador de textos, um editor de textos e uma planilha, os autores criaram a CAP-APL, uma plataforma para a criação e uso de arquiteturas pedagógicas para a aprendizagem de Português e Libras.

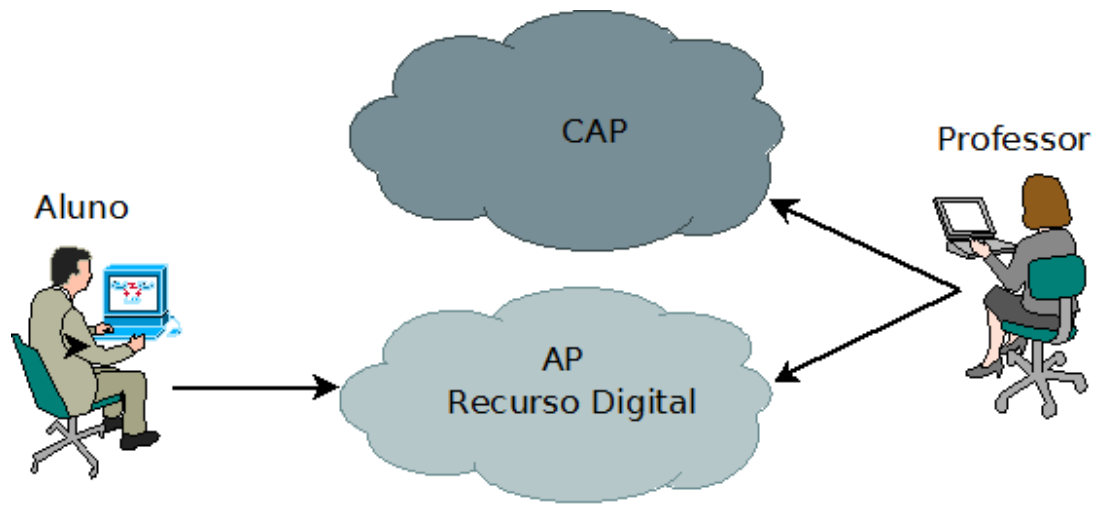

Figura 3. Esquema de uso da plataforma CAP-APL.

A Figura 3 apresenta um esquema (didático) de uso da Plataforma CAP-APL, com seus atores, onde se vê: o professor criando arquiteturas pedagógicas (APs) na plataforma, com a alocação dos recursos digitais apropriados para cada AP, e o aluno usando as APs criadas pelo professor. Nesse uso, o aprendiz desenvolve as atividades planejadas pelo professor, em cada AP, seguindo o método (como fazer cada atividade) proposto na AP e com o suporte dos recursos digitais alocados na AP. 
VI Congresso Brasileiro de Informática na Educação (CBIE 2017)

Anais do XXVIII Simpósio Brasileiro de Informática na Educação (SBIE 2017)

\section{Arquiteturas pedagógicas para a aprendizagem de Português e Libras}

Para validação da CAP-APL, foram instanciadas três APs, uma para a aprendizagem de Português, uma para a aprendizagem de Libras e uma para a aprendizagem de tradução de Português para Libras, conforme segue.

\subsection{AP1 - Aprendendo a etiquetar palavras de textos em Português}

Objetivo de aprendizagem: Aprender a classificar as palavras da língua portuguesa segundo sua distribuição morfossintática (classe gramatical, gênero, número).

Atividade: Analisar textos da língua portuguesa e etiquetar cada palavra segundo sua distribuição morfossintática.

Método: A partir de um texto disponível na AP, os alunos devem fazer a etiquetagem morfossintática das palavras dele. Os aprendizes podem usar o etiquetador morfossintático TreeTagger (recurso digital disponível), de modo a analisarem a etiquetagem das palavras do texto e anotarem dúvidas a serem discutidas com o professor.

Recursos digitais: Um visualizador e um etiquetador (etiquetador morfossintático TreeTagger, da biblioteca de recursos digitais da CAP-APL) de texto em Português; um visualizador de texto para a apresentação do texto etiquetado.

Exemplo de uso da AP1: Para exemplificar o uso do etiquetador de palavras, foi dada como entrada a sentença "A mulher vê o lobo", que produz a seguinte sequência de tags: " $<D A 0$; NCFS; VMI;DA0;NCMS $>$ ". A Tabela 1 apresenta detalhadamente o significado de cada uma dessas tags.

Tabela 1. Significado das tags geradas pelo etiquetador.

\begin{tabular}{|c|c|}
\hline Tag & Significado \\
\hline DA0 & Determinante (Artigo) \\
\hline NCFS & Substantivo comum feminino singular \\
\hline VMI & Verbo principal no modo indicativo \\
\hline DA0 & Determinante (Artigo) \\
\hline NCMS & Substantivo comum masculino singular \\
\hline
\end{tabular}

\subsection{AP2: Interpretando expressões gesticuladas em Libras}

Objetivo de aprendizagem: Aprender a interpretar sinais Libras.

Atividade: A partir de vídeos com gesticulações animadas de palavras/expressões Libras, cada aprendiz interpreta o conteúdo dos vídeos para o Português.

Método: Acessando uma planilha disponibilizada na AP, cada aprendiz visualiza os vídeos gravados, com gesticulação de alguma palavra/expressão Libras, e escreve a tradução para o Português dessa palavra/expressão, na linha correspondente da planilha.

Recursos digitais: Uma planilha elaborada com os nomes dos estudantes da turma e os vídeos gravados com a gesticulação de palavras/expressões Libras, disponíveis a toda a turma, onde cada aprendiz pode inserir a tradução de Libras 
VI Congresso Brasileiro de Informática na Educação (CBIE 2017)

Anais do XXVIII Simpósio Brasileiro de Informática na Educação (SBIE 2017)

para o Português da palavra/expressão registrada no vídeo; um visualizador de vídeos da biblioteca de recursos digitais (BRD) da CAP-APL.

Exemplo de uso da AP2: A Figura 4 apresenta a tela da AP disponível ao estudante. Nessa tela o estudante pode visualizar o vídeo do professor (1) e pode revê-lo sempre que desejar, clicando em 'Replay' (2). Após interpretar o vídeo em Libras selecionado pelo professor e editar a tradução (3), ou seja, o texto em Português, ele clica em 'Enviar Resposta' (4) para salvar a resposta e submetê-la ao professor.

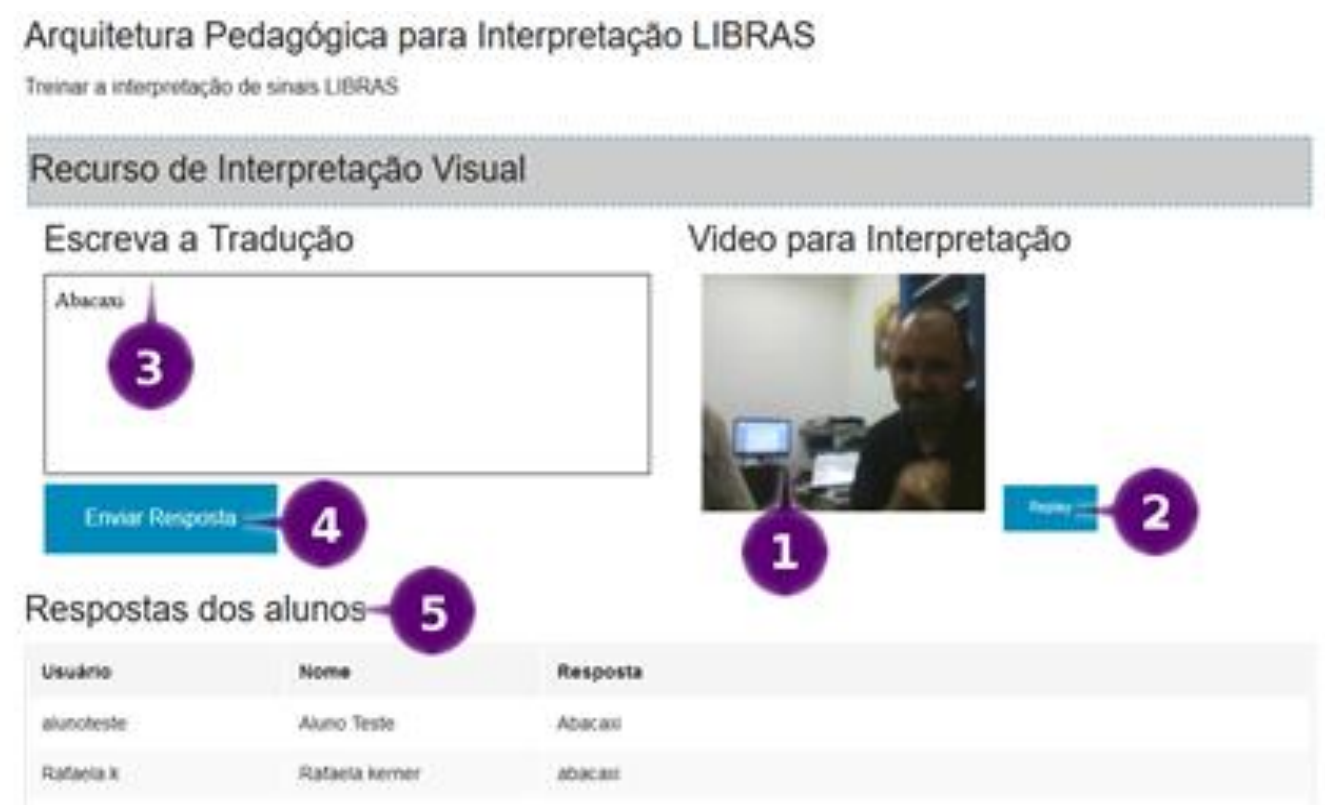

Figura 4. Tela de comunicação do recurso de interpretação visual.

\subsection{AP3: Traduzindo expressões do Português para Libras}

Objetivo de aprendizagem: Aprender a traduzir expressões do Português para Libras de sentença existentes na MT.

Atividade: Traduzir de expressões do Português para Libras.

Método: O estudante grava um vídeo com a gesticulação, feita por ele, da expressão Libras correspondente à expressão em Português fornecida. O estudante pode usar o tradutor de Português para Libras para visualizar a tradução das expressões em Português para Libras, de modo a aprender a tradução correspondente.

Recursos digitais: Um gravador de vídeos e um tradutor de Português para Libras, da BRD/CAP-APL.

Exemplo de uso da AP3: Na tradução de Português para Libras da sentença "A mulher vê o lobo", o tradutor usa o padrão definido pela sequência de tags “ $<$ DA0;10243137;2167052;DA0;2114100>”. Esse padrão descreve sentenças equivalentes à sentença de entrada. A Tabela 2 apresenta detalhadamente o significado de cada tag da expressão de saída.

A sequência de tags acima é então convertida para uma expressão de equivalência em LIBRAS, onde são eliminados os determinantes, gerando a sequência de tags $<10243137 ; 2167052 ; 2114100>$, equivalente à glosa "MULHER VER LOBO" 
VI Congresso Brasileiro de Informática na Educação (CBIE 2017)

Anais do XXVIII Simpósio Brasileiro de Informática na Educação (SBIE 2017)

que é exibida via uma sequência de vídeos, com a forma gestual animada em Libras dessa glosa. Uma frase como "a mulher observou o lobo" também geraria a mesma tradução, pois são parte do mesmo conjunto de synsets sinônimos.

Tabela 2. Significado das tags usadas no tradutor.

\begin{tabular}{|c|c|}
\hline Tag & Significado \\
\hline DA0 & Determinante (Artigo) \\
\hline 10243137 & $\begin{array}{c}\text { Synset da WordNet referente ao conjunto de substantivos } \\
\text { sinônimos que incluem o substantivo" mulher". }\end{array}$ \\
\hline 2167052 & $\begin{array}{c}\text { Synset da WordNet referente ao conjunto de verbos } \\
\text { sinônimos que incluem o verbo "ver". }\end{array}$ \\
\hline DA0 & Determinante (Artigo) \\
\hline 2114100 & $\begin{array}{c}\text { Synset da WordNet referente ao conjunto de substantivos } \\
\text { sinônimos que incluem o substantivo "lobo". }\end{array}$ \\
\hline
\end{tabular}

\section{Análise e testes das arquiteturas pedagógicas}

Os testes foram realizados em uma aula de 50 minutos, com dois professores intérpretes em um laboratório de informática com computadores munidos de câmeras digitais, microfone e acesso à internet. O navegador utilizado foi o Mozilla Firefox, versão 36.

A plataforma CAP-APL foi avaliada a partir do uso de técnicas que permitem analisar os dados, levantados por meio de questionários, sobre o perfil dos usuários e o uso do sistema. Nesses testes buscou-se obter informações acerca da efetividade do software, sob o ponto de vista de seus usuários (Cybis et al. 2007).

O questionário de usabilidade nos moldes apresentados, demonstrou que os professores relatam existir diferenças entre a prática de suas atividades de sala de aula habituais e a realização delas no sistema. Não demonstraram ter nenhuma dificuldade em realizar atividades virtuais de modo geral. A pontuação média atribuída pelos usuário para a usabilidade geral foi de $70 \%$.

O teste funcional é também chamado de teste baseado em especificações ou teste caixa-preta (Pezzé, 2008), busca-se neste experimento enxergar o fluxo de dados e seu efetivo uso. No teste funcional os usuários da CAP sugerem algumas melhorias dos recursos digitais. A CAP em si funcionou adequadamente, mas é visível a dependência das APs em relação aos recursos que foram especialmente desenvolvidos para atendêlas, o que justifica a necessidade de ajustes/adaptações de cada recurso alocado para uma AP, por meio de ações de configuração feitas pelo professor, como apresentado na Figura 1.

\section{Considerações finais}

Este artigo apresentou uma plataforma web, projetada, implementada e testada pelos autores, para a criação e uso de arquiteturas pedagógicas para a aprendizagem de Português e de Libras - a CAP-APL. Apresentou também três arquiteturas pedagógicas configuradas nessa plataforma, sem a necessidade de conhecimento de programação.

Com a facilidade que um professor (de Português ou Libras), leigo em programação de computadores, encontra em configurar APs na plataforma CAP-APL, e com a motivação que existe nos aprendizes quando usam recursos computacionais e web, acreditamos que essa nova proposta de tecnologia educacional contribua para a 
VI Congresso Brasileiro de Informática na Educação (CBIE 2017)

Anais do XXVIII Simpósio Brasileiro de Informática na Educação (SBIE 2017)

aprendizagem dessas duas línguas.

\section{Agradecimento}

Os autores agradecem à FAPES (Fundação de amparo e pesquisa do Espírito Santo) e à CAPES (Coordenação de Aperfeiçoamento de Pessoal de Nível Superior) pelo apoio nesta pesquisa.

\section{Referências}

Almeida, R., Tavares, O. L., Reinoso, L. F. (2016) "CAPCOM - Construtor de Arquiteturas Pedagógicas para Dinâmicas Colaborativas com Multimídia. In: SBSC $13^{\circ}$ Simpósio Brasileiro de Sistemas Colaborativos". In: XXXVI Congresso da Sociedade Brasileira de Computação. Porto Alegre: SBC, págs. 1423-1436.

Carvalho, M. J. S., Nevado, R. A., and Menezes, C. S. (2005) "Arquiteturas Pedagógicas para Educação a Distância: Concepções e Suporte Telemático”, In: XVI Simpósio Brasileiro de Informática na Educação, Juiz de Fora-MG. Brasil. págs. 351-360.

Cervo, A. L., Bervian, P. A. and Silva, R. (2007) "Metodologia Científica". 6a ed. São Paulo: Pearson Prentice Hall.

Coradine, L. C., Albuquerque, F. C., Silva, Brito, P. H. S., Ferreira, A., Madeiro, J. M. and Perreira, M. C. (2004) "Sistema Falibras: Tradutor do Português (falado ou escrito) para Libras (gestual e animada)", In: XXI Simpósio Brasileiro de Telecomunicações.

Cybis, W., Beitol, A. H., Faust., R. (2007) "Ergonomia e usabilidade: Conhecimentos, métodos e aplicações". São Paulo: Editora Novatec.

Freire, P.(1998) Pedagogia da Autonomia: saberes necessários à prática educativa. Rio de Janeiro: Paz e Terra.

Menezes, C. S., Nevado, R. A., Castro Júnior, A. N., Santos, L. N. (2008) "MOrFEU Multi-Organizador Flexível de Espaços Virtuais para Apoiar a Inovação Pedagógica em EAD”. In: Anais XIX Simpósio Brasileiro de Informática na Educação, págs. 451-460.

Nascimento, C. V., Menezes. C. S. and Tavares, O. L. (2012) "Uma arquitetura de acessibilidade para ambientes virtuais". In: Memorias del XVII Congresso Internacional de Informática Educativa, TISE, Santiago-Chile, págs. 353-358.

Pereira, B., Almeida, R., Tavares, O. L. and Menezes, C. S. (2015) “AM: Uma Plataforma Digital para Criação e Uso de Veículos de Comunicação Locativos para Atividades Pedagógicas." In Anais do Simpósio Brasileiro de Informática na Educação. Vol. 26. No. 1.

Piaget, J. (1985). O possível e o necessário - evolução dos possíveis na criança. Porto Alegre, Artes Médicas.

Pezzè, M. and Young, M. (2008) "Teste e análise de software: processos, princípios e técnicas". Porto Alegre: Bookman.

Reinoso, L. F. (2016). Uma plataforma para construção e uso de arquiteturas pedagógicas para aprendizagem de libras. Dissertação de Mestrado; PPGI/UFES, 
VI Congresso Brasileiro de Informática na Educação (CBIE 2017)

Anais do XXVIII Simpósio Brasileiro de Informática na Educação (SBIE 2017)

Vitória-ES, Maio.

Reinoso, L. F. and Tavares, O. L. (2015) "MVLIBRAS: ambiente digital para comunidades de aprendizagem com recursos inclusivos para surdos". In: Anais do XXVI Simpósio Brasileiro de Informática na Educação. Págs 772-881. MaceióAlagoas.

Reinoso, L. F. ; Almeida, R. F. ; Tavares, O. L. (2016) Modelo CAP: Construtor de Arquiteturas Pedagógicas. In: Congresso Internacional de Informática Educativa, 2016, Chile. Actas do Congresso Internacional de Informática Educativa. Santiago/Chile: Jaime Sánchez, v. 12, p. 89-94.

Santarosa, L. M. C., Vieira, Maristela C., Correa, Y. and Biazus, M. C. (2014) "Para além da interação: o papel de aplicativos como ProDeaf e HandTalk na constituição do sujeito surdo" In: Seminário Nacional de Inclusão Digital, Passo Fundo. Anais III SENID - $3^{\circ}$ Seminário Nacional de Inclusão Digital. Passo Fundo: Editora UPF.

Santos, L. N., Jr, A. N. C. and Menezes, C. S. (2010) "MOrFEu: criando ambientes virtuais flexíveis na WEB para mediar a colaboração". In Congresso Iberoamericano de Informática Educativa. Páginas 114-121.

WordNet (2015) "WordNet: A lexical database for English". Acessado em 15 de Abril de 2017. Disponível em: $<$ http://wordnet.princeton.edu/ $>$. 